\title{
Control of chemotherapy-induced nausea in patients receiving outpatient cancer chemotherapy
}

\author{
Hirotoshi Iihara $^{1} \cdot$ Hironori Fujii $^{1}$ Chiaki Yoshimi ${ }^{1} \cdot$ Maya Yamada $^{1} \cdot$ Akio Suzuki $^{1}$. \\ Nobuhisa Matsuhashi ${ }^{2} \cdot$ Takao Takahashi $^{2} \cdot$ Kazuhiro Yoshida $^{2} \cdot$ Yoshinori Itoh $^{1}$
}

Received: 7 August 2015 / Accepted: 18 September 2015 / Published online: 16 October 2015

(c) The Author(s) 2015. This article is published with open access at Springerlink.com

\begin{abstract}
Background Control of chemotherapy-induced nausea is still incomplete, regardless of adherence to the antiemetic guideline. The present study was designed to assess the control rates of nausea and vomiting in the outpatient chemotherapy clinic and to determine risk factors for nausea.

Methods A single-center prospective observational study was carried out in 779 patients who received 5511 chemotherapy cycles from January 2013 to December 2014 in the outpatient chemotherapy clinic. A checklist for adverse events was provided to all patients, and nausea and vomiting were monitored on the next visit. Complete protection from nausea and vomiting during acute (within $24 \mathrm{~h}$ ) and delayed (during 2-7 days) periods was assessed.

Results Under the condition of 76-99\% rates of adherence to the Japanese Society of Clinical Oncology guideline for antiemesis, the rates of complete protection from acute and delayed nausea in the first cycle of chemotherapy were $60 \%$ and $45 \%$, respectively, for high emetic risk chemotherapy (HEC), and $85 \%$ and $70 \%$ for moderate emetic risk chemotherapy (MEC). The rates were improved in the overall cycles. On the other hand, vomiting was well controlled, in which complete protection ranged from $83 \%$ (HEC) to $99 \%$ (minimum). A multivariate analysis indicated that being female, age less than 60 years, high or moderate risk chemotherapy, and anthracycline/
\end{abstract}

Hirotoshi Iihara

dai0920@gifu-u.ac.jp

1 Department of Pharmacy, Gifu University Hospital, Gifu, Japan

2 Department of Surgical Oncology, Gifu University Graduate School of Medicine, Gifu, Japan cyclophosphamide (A/C) were significant risks for overall nausea. Indeed, the control of delayed nausea was extremely poor in the first cycle of A/C, although there was no difference in the control of nausea among MEC.

Conclusion Antiemetic medication in consideration of the risk factors is required to improve the control of nausea.

Keywords Outpatient cancer chemotherapy $\cdot$ Nausea · Emetic risk $\cdot$ Risk analysis $\cdot$ Adherence to guideline

\section{Introduction}

Chemotherapy-induced nausea and vomiting (CINV) were the first and second most distressing adverse events in the past [1]. Nausea and vomiting severely impair the patient's quality of life, which may lead to the discontinuance of therapy. However, the rank order of nausea and vomiting has dropped [2] since the development of 5-hydroxytryptamine- $3\left(5-\mathrm{HT}_{3}\right)$ receptor antagonists and the prevalence of the American Society of Clinical Oncology (ASCO) clinical practice guideline for antiemesis [3]. Subsequently, with the development of novel classes of antiemetic drugs such as neurokinin $1\left(\mathrm{NK}_{1}\right)$ receptor antagonists, including aprepitant, and palonosetron, a second-generation $5-\mathrm{HT}_{3}$ receptor antagonist, the antiemetic guideline has been revised by several international societies for clinical oncology, including ASCO [4], Multinational Association of Supportive Care in Cancer (MASCC) [5], National Comprehensive Cancer Network (NCCN) [6], and Japanese Society of Clinical Oncology (JSCO) [7].

However, guideline-consistent antiemetic medication is not always widely used in clinical practice, a so-called evidence-practice gap [8]. Gomez et al. [9] reported, in patients who received high emetic risk chemotherapy 
(HEC) or moderate emetic risk chemotherapy (MEC), that the use of 5- $\mathrm{HT}_{3}$ receptor antagonist with dexamethasone is $60-90 \%$, whereas the use of a $\mathrm{NK}_{1}$ antagonist is much less common $(<10 \%)$. Hori et al. [10] also reported by a nationwide survey of 9978 patients receiving 81,739 chemotherapy cycles from 39 Japanese hospitals that the rates of adherence to the JSCO guideline during acute and delayed periods are $28.1 \%$ and $9.7 \%$, respectively, for HEC, and $7.2 \%$ and $6.9 \%$, respectively, for MEC.

It has been demonstrated that adherence to the antiemetic guideline improves the control of CINV [11-13]. Chan et al. [11] reported in 361 breast cancer patients receiving anthracycline-based chemotherapy that the adherence to the antiemetic guideline is $57.9 \%$ and that the complete control of CINV is better in the guideline-consistent group than in the guidelineinconsistent group, indicating that adherent patients were more likely to achieve complete control of CINV [adjusted odds ratio (OR) 1.74, $95 \%$ confidence interval (CI) 1.01-3.01, $P=0.048$ ]. Aapro et al. [12] also reported in 991 patients receiving the first cycle of HEC or MEC that the complete response (no vomiting and no rescue) is significantly better in the guideline-consistent group than in the guideline-inconsistent group $(59.9 \%$ vs. $50.7 \%, P=0.008)$, resulting in the adjusted odds ratio of 1.43 (95\% CI 1.04-1.97, $P=0.027$ ). We also previously reported in 125 colorectal cancer patients receiving the first cycle of MEC such as levofolinate, fluorouracil, oxaliplatin (mFOLFOX6) and levofolinate, fluorouracil, irinotecan (FOLFIRI) regimen that the complete control of nausea but not vomiting is significantly better in the guidelineconsistent group than in the guideline-inconsistent (lack of dexamethasone on days 2 and 3) group (74\% vs. $56 \%$ for nausea, $P<0.05$; $94 \%$ vs. $91 \%$ for vomiting) [14].

On the other hand, cancer chemotherapy is currently shifting from inpatient admission to the outpatient setting. Chemotherapy-induced vomiting is almost preventable in the outpatient setting by the addition of $\mathrm{NK}_{1}$ receptor antagonists and $5-\mathrm{HT}_{3}$ receptor antagonists to the standard medication, although nausea remains a distressing adverse drug reaction $[15,16]$. In the present study, the antiemetic medication consistent with the JSCO guideline has been implemented in our outpatient chemotherapy clinic, and the rates of complete protection of CINV were subsequently investigated. Risk analysis for overall nausea was also carried out.

\section{Patients and methods}

\section{Patients}

There were 9590 visits for cancer chemotherapy in our outpatient chemotherapy clinic during the 2 years from January 2013 to December 2014; among these, chemotherapy was carried out in 8206 visits, thereby indicating a $14.4 \%$ discontinuance rate. The actual number of patients counted by the patient ID number was 779 and the number of chemotherapy cycles was 5577 . Health professionals such as pharmacists and nurses were in charge of provision of drug information and safety precaution in daily life and of monitoring adverse drug reactions to all patients in our outpatient chemotherapy clinic. Patient consultation was carried out in 8206 visits (100\%), but the CINV data were obtained from 5511 chemotherapy cycles. Thus, data from $98.8 \%$ of the chemotherapy cycles were subjected to analysis in the present study.

The present study was carried out in accordance with the guidelines for the care for human study adopted by the Ethics Committee of the Gifu Graduate School of Medicine, and notified by the Japanese Government (approved no. 26-153 of the Institutional Review Board).

\section{Adherence to the Japanese guideline for the use of antiemetic drugs}

According to the JSCO clinical practice guideline for antiemesis, the use of antiemetic drugs was promoted for prevention of CINV: the combination of $5-\mathrm{HT}_{3}$ receptor antagonist, aprepitant, and dexamethasone was used before chemotherapy and a combination of aprepitant and dexamethasone was provided on days 2 and 3, and dexamethasone on day 4 for high emetic risk chemotherapy (HEC), a combination of 5- $\mathrm{HT}_{3}$ receptor antagonist and dexamethasone was taken before chemotherapy, and dexamethasone was prescribed on days 2 and 3 for moderate emetic risk chemotherapy (MEC), and dexamethasone was administered only before chemotherapy for low emetic risk chemotherapy. No routine antiemetic drug was provided for prevention of minimum risk chemotherapy. Health professionals made extensive efforts in facilitating the use of appropriate antiemetic premedication by inclusion of antiemetic regimens into the prescription order for chemotherapy regimens or by proposing the prescription of antiemetic drugs to physicians. Adherence to the Japanese antiemetic guideline in both acute and delayed periods was evaluated. In the case of the dose of dexamethasone, the guideline recommends $8 \mathrm{mg} /$ day in the delayed period for HEC and MEC. In the present study, however, $4 \mathrm{mg}$ /day on days $2-3$ for MEC was regarded as positive for adherence because previous findings indicated that the control of delayed nausea is improved by $20 \%$ by the addition of $4 \mathrm{mg} /$ day of dexamethasone on days $2-3$, when compared with no treatment with dexamethasone in patients receiving MEC [14].

\section{Evaluation of chemotherapy-induced nausea}

All patients were provided with a checklist for daily check of adverse events on their first visit to the outpatient 
chemotherapy clinic. Using the checklist, patients checked daily their nausea by numeric rating scale $(0-10)$ and the number of vomiting episodes up to 7 days after chemotherapy. Pharmacists and nurses recorded the control of nausea and vomiting on the electronic medical record after verifying the data or hearing results from patients on the next visit. Complete protection from nausea (NRS scale $<1$ ) and vomiting (no episode) during acute (within $24 \mathrm{~h}$ after chemotherapy) and delayed (during 2-7 days after chemotherapy) periods was assessed in patients receiving the first cycle of chemotherapy or in those with overall cycles of chemotherapy.

\section{Risk analysis for chemotherapy-induced nausea during overall period}

Demographics of patients were compared between patients who revealed acute and delayed nausea and those who showed complete protection from nausea. Subsequently, uni- as well as multivariate logistic regression analyses were carried out to determine the risk for incomplete protection from for nausea or vomiting during the overall period. Odds ratio (OR) and $95 \%$ confidence interval (CI) were determined. The cutoff value of age was determined by the Youden index or the distance method in the receiver operating characteristic curve (ROC) analysis. In the Youden index, cutoff age was estimated from the maximum value of (sensitivity + specificity -1 ), whereas in the distance method, cutoff value was predicted from the minimum value for square root $\left[(1-\text { sensitivity })^{2}+(1-\right.$ specificity $\left.\left.)^{2}\right)\right]$, according to the method described earlier $[17,18]$.

\section{Statistical analyses}

Data were analyzed using IBM SPSS Statistics ver. 22 (IBM Japan Services, Tokyo, Japan) and Graph Pad Prism version 6.0 (Graph Pad Software, San Diego, CA, USA). Parametric variables were analyzed using the $t$ test, and nonparametric data were analyzed by the Mann-Whitney $U$ test or the chi-square test. Multiple comparisons for the control of nausea and vomiting were carried out by Kruskal-Wallis test followed by Scheffe's test. A $P$ value less than 0.05 was considered statistically significant.

\section{Results}

\section{Demographics of patients}

Demographics of the patients are shown in Table 1. Seven hundred and seventy-nine patients received 5511 chemotherapy cycles during 2 years from January 2013 to December 2014 in our outpatient chemotherapy clinic. The average chemotherapy cycle was 8.3 cycles. The most common type of cancer was colorectal cancer $(26 \%$ of patients and $35 \%$ of all chemotherapy cycles), followed by lung cancer (14\% and $12 \%)$, breast cancer (14\% and $17 \%$ ), gastric cancer (13\% and $12 \%)$, liver/gallbladder/pancreas cancer $(10 \%$ and $9 \%)$, hematological cancer $(9 \%$ and $5 \%$ ), gynecological cancer (6\% and $5 \%$ ), and head and neck cancer ( $3 \%$ and $2 \%$ ). The emetic risk of the chemotherapy regimens included HEC (291 cycles, $5 \%$ ), MEC (2184 cycles, $40 \%$ ), low risk (2162 cycles, $39 \%)$, and minimum risk ( 874 cycles, $16 \%$ ).

\section{Control of nausea and vomiting}

The rates of complete protection from nausea and vomiting during acute and delayed periods in the first cycle and overall cycles are shown in Fig. 1. In the first cycle of chemotherapy, the rate of adherence to the Japanese clinical practice guideline for prevention of CINV ranged from $76 \%$ (HEC) to $99 \%$ (low risk). Under such a condition, patients receiving HEC showed poor control of nausea during acute and delayed periods, although vomiting was favorably controlled (83-85\% of complete protection). The rates of complete protection from acute and delayed nausea were $61 \%$ and $44 \%$, respectively, for HEC, and $87 \%$ and $68 \%$, respectively, for MEC, in which the rates increased in a manner dependent on the emetic risk of the chemotherapy. In the overall cycles, the control of nausea in HEC was greatly improved, in which the complete protection from acute and delayed nausea was $77 \%$ and $62 \%$, respectively.

\section{Comparison of demographics between patients who showed no nausea and those with nausea}

To determine the risk of chemotherapy-induced nausea, the demographics of patients were compared between those with and without complete protection from nausea in 608 patients who received the first cycle of chemotherapy. As shown in Table 2, significant differences in gender, age, proportion of HEC/MEC and anthracycline/cyclophosphamide $(\mathrm{A} / \mathrm{C})$ regimen, and type of cancer were observed between the two groups. Females were more often affected (67\% vs. $48 \%, P<0.001$ ), patient age was younger $(56.7$ vs. 63.4 years), and the proportion of $\mathrm{A} / \mathrm{C}$ regimen (18\% vs. $2 \%, P<0.001)$ and HEC/MEC (64 \% vs. $36 \%$ ) in patients without complete protection from nausea. Moreover, the percentage of breast cancer patients was significantly higher $(31 \%$ vs. $18 \%, P<0.001)$ in patients with nausea than those without it.

On the other hand, adherence to the antiemetic guideline was not different between the two groups $(92.4 \%$ vs. $93.6 \%, P=0.755)$. 
Table 1 Demographics of patients

\begin{tabular}{|c|c|c|c|c|}
\hline Number of patients (male/female) & & & \multicolumn{2}{|c|}{$779(391 / 388)$} \\
\hline Age (average, $\min / \max$ ) & & & \multicolumn{2}{|c|}{$63.4(18 / 88)$} \\
\hline Body surface area (average, SD) & & & \multicolumn{2}{|c|}{$1.56 \pm 0.40$} \\
\hline Serum creatinine $(\mathrm{mg} / \mathrm{dl}$, average, $\mathrm{SD})$ & & & \multicolumn{2}{|c|}{$0.72 \pm 0.27$} \\
\hline Number of chemotherapy courses & & & \multicolumn{2}{|l|}{5511} \\
\hline Cancer type & Number of patients & $\%$ & Number of courses & $\%$ \\
\hline Colorectal & 201 & 25.8 & 1923 & 34.9 \\
\hline Lung & 107 & 13.7 & 645 & 11.7 \\
\hline Breast & 105 & 13.5 & 935 & 17.0 \\
\hline Gastric & 101 & 13.0 & 680 & 12.3 \\
\hline Liver/gallbladder/pancreas & 81 & 10.4 & 510 & 9.3 \\
\hline Hematological & 73 & 9.4 & 270 & 4.9 \\
\hline Gynecological & 49 & 6.3 & 259 & 4.7 \\
\hline Head and neck & 26 & 3.3 & 117 & 2.1 \\
\hline Esophageal & 15 & 1.9 & 49 & 0.9 \\
\hline Urological & 10 & 1.3 & 89 & 1.6 \\
\hline Brain & 9 & 1.2 & 25 & 0.5 \\
\hline Sarcoma & 1 & 0.1 & 1 & 0.02 \\
\hline Dermatological & 1 & 0.1 & 8 & 0.1 \\
\hline Average chemotherapy courses (min/max) & $8.3(1 / 91)$ & & & \\
\hline Emetic risk of chemotherapy & $n$ & & & $\%$ \\
\hline High & 29 & & & 5.3 \\
\hline Moderate & 218 & & & 39.6 \\
\hline Low & 2162 & & & 39.2 \\
\hline Minimum & 872 & & & 15.9 \\
\hline
\end{tabular}

\section{Risks for chemotherapy-induced overall nausea or vomiting}

Because age was significantly different between patients with and without overall nausea, an ROC curve was plotted for sensitivity versus $1-$ specificity. The area under the curve (AUC) was 0.658 (95\% CI, 0.607-0.709), indicating low accuracy prediction [17]. Using the ROC curve method, the cutoff age was predicted to be 58.5 years old (Youden index, $72.4 \%$ sensitivity vs. $55.9 \%$ specificity) or 61.5 years old (distance method, $63.6 \%$ sensitivity vs. $62.7 \%$ specificity). Thus, the cutoff age was set to 60 years for nausea. For vomiting, AUC of ROC curve was 0.721 (95\% CI, 0.629-0.813), indicating moderate accuracy prediction [17]. ROC analysis indicated that the cutoff age was 49.5 years old (Youden index as well as distance method, $84.5 \%$ sensitivity vs. $56.4 \%$ specificity). Thus, the cutoff age was set to 50 years old for vomiting.

As presented in Table 3, multivariate analysis showed that four factors such as female gender (OR 1.615; $95 \%$ CI, 1.022-2.552; $P=0.004)$, age under 60 years (OR $2.303 ; 1.525-3.477 ; P<0.001)$, inclusion of HEC/MEC (OR 2.321; 1.489-3.617; $P<0.001$ ), and A/C regimen (OR
4.955; 1.863-13.18; $P=0.001)$ were significant risks for overall nausea.

On the other hand, female gender (OR 3.151; $95 \% \mathrm{CI}$, 1.213-8.183; $P=0.018$ ), age under 50 years (OR 5.803; 2.667-12.63, $P<0.001$ ), and inclusion of HEC/MEC (OR $2.993 ; 1.245-7.195 ; P=0.014)$ were found to be significant risks for overall vomiting by multivariate analysis. Adherence to the antiemetic guideline did not reduce the risk for overall nausea or vomiting (OR 0.960; 0.4442.076, $P=0.918$ for nausea; OR 0.539 ; $0.138-2.110$, $P=0.375$ for vomiting).

\section{Comparison of the control of nausea and vomiting among various HEC and MEC regimens}

As risk analysis indicated that $\mathrm{HEC} / \mathrm{MEC}$ and $\mathrm{A} / \mathrm{C}$ regimen were significant risks for chemotherapy-induced nausea, the rates of complete protection from nausea and vomiting during acute and delayed periods were compared among HEC and MEC regimens in patients who received the first cycle of chemotherapy. As shown in Fig. 2, the rate was significantly lower in $\mathrm{A} / \mathrm{C}$ regimen (46\% and $24 \%$ for acute and delayed periods, respectively) as compared with other regimens, regardless 


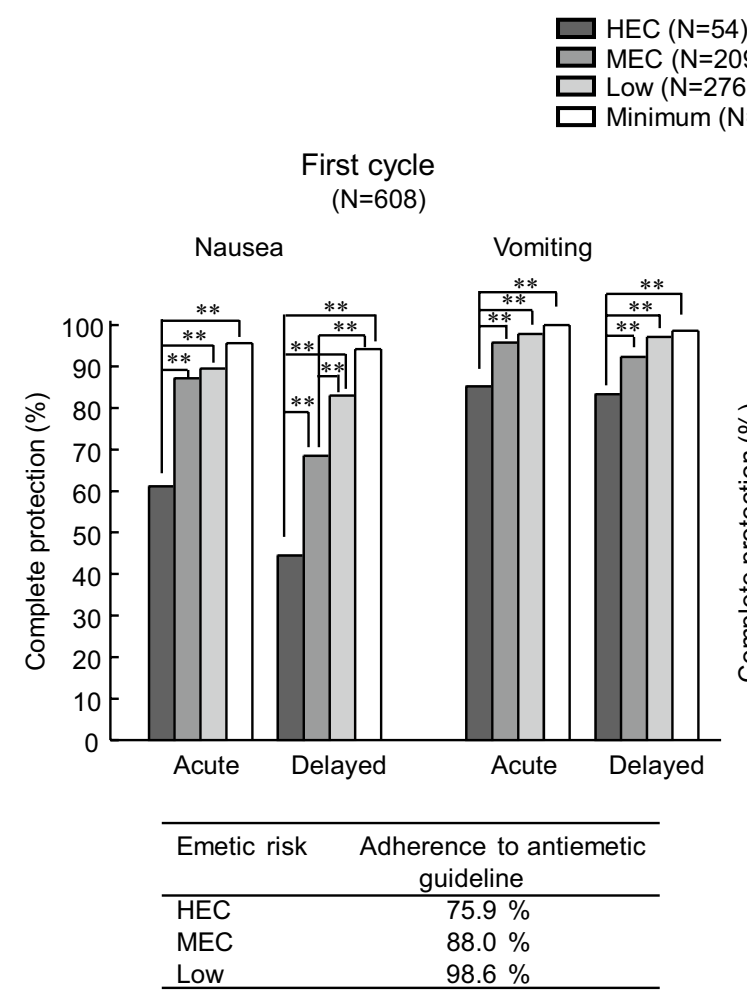

Fig. 1 Complete protection from nausea and vomiting during acute and delayed periods in patients receiving high emetic risk chemotherapy $(H E C)$, moderate emetic risk chemotherapy $(M E C)$, low risk, or minimum risk of chemotherapy as the first cycle or the overall cycles

of $100 \%$ adherence to the guideline-recommended antiemetic medication. In contrast, the control of nausea was favorable for a cisplatin (CDDP)-containing regimen (94\% and $88 \%$ for acute and delayed periods, although the dose of CDDP was low $\left(25 \mathrm{mg} / \mathrm{m}^{2}\right.$ in CDDP/gemcitabine for gallbladder cancer or $30 \mathrm{mg} / \mathrm{m}^{2}$ in CDDP/irinotecan for gastric cancer).

\section{Change in the control of nausea and vomiting in $\mathrm{A} / \mathrm{C}$ regimen after repeated treatment cycles}

Although the complete protection from acute and delayed nausea in the first cycle of $\mathrm{A} / \mathrm{C}$ chemotherapy was poor (46\% for acute nausea and $24 \%$ for delayed nausea), the rates were improved in the second and third cycles of chemotherapy (Fig. 3). There were significant differences in the rates of delayed nausea and acute as well as delayed vomiting (Kruskal-Wallis test). On the other hand, dose reduction was not carried out in the first cycle in all patients but was performed in one patient in the second cycle (15\% reduction) as well as in the third cycle $(15 \%$ reduction).

\section{Discussion}

In the present study, we surveyed the rate of control of CINV in 779 patients who received 5511 cycles of chemotherapy regimens in our outpatient cancer chemotherapy clinic. Among them, patients with gastrointestinal cancer were predominant (51\% of patients and $57 \%$ of chemotherapy cycles).

According to the clinical practice guidelines for antiemesis formulated by ASCO [4], MASCC/ESMO [5], NCCN [6], and JSCO [7], palonosetron, a long-acting secondgeneration $5-\mathrm{HT}_{3}$ receptor antagonist, is recommended for use in HEC and MEC; however, in the present study, the first generation of $5-\mathrm{HT}_{3}$ receptor antagonists such as granisetron was predominantly prescribed. In the present study, health professionals, including pharmacists and nurses, interviewed all patients and monitored adverse drug reactions. In addition, we checked the prescription for antiemetic medication and aggressively promoted the appropriate use of antiemetic drugs. As a consequence, adherence to the clinical practice guideline for the use of antiemetic drugs was generally high (76\% for HEC, 
Table 2 Comparison of demographics of patients with nausea during overall period in 608 patients who received the first cycle of chemotherapy

\begin{tabular}{|c|c|c|c|c|c|}
\hline & \multicolumn{2}{|c|}{ With nausea during overall period $(n=158)$} & \multicolumn{2}{|c|}{ Without nausea during overall period $(n=450)$} & $P$ \\
\hline Ratio of female (female/male) & \multicolumn{2}{|l|}{$67.1(106 / 52)$} & \multicolumn{2}{|l|}{$47.8(215 / 235)$} & $<0.001^{\mathrm{a}}$ \\
\hline Age (years) & \multicolumn{2}{|l|}{$56.7(18-84)$} & \multicolumn{2}{|l|}{$63.4(35-88)$} & $<0.001^{\mathrm{a}}$ \\
\hline Height $(\mathrm{cm})$ & \multicolumn{2}{|l|}{$160.1 \pm 7.5$} & \multicolumn{2}{|l|}{$160.3 \pm 8.5$} & $0.775^{\mathrm{c}}$ \\
\hline Body weight (kg) & \multicolumn{2}{|l|}{$55.0 \pm 10.7$} & \multicolumn{2}{|l|}{$55.8 \pm 10.8$} & $0.464^{\mathrm{c}}$ \\
\hline \multirow[t]{2}{*}{ Serum creatinine $(\mathrm{mg} / \mathrm{dl})$} & \multicolumn{2}{|l|}{$0.69 \pm 0.23$} & \multicolumn{2}{|l|}{$0.72 \pm 0.23$} & $0.170^{\mathrm{c}}$ \\
\hline & $n$ & $\%$ & $n$ & $\%$ & $P$ \\
\hline \multicolumn{6}{|l|}{ Regimens/anticancer drug } \\
\hline $\mathrm{A} / \mathrm{C}$ & 28 & 17.7 & 9 & 2.0 & $<0.001^{\mathrm{a}}$ \\
\hline $\mathrm{CHOP}$ & 3 & 1.9 & 5 & 1.1 & $0.733^{\mathrm{a}}$ \\
\hline Oxaliplatin & 29 & 18.4 & 61 & 13.6 & $0.183^{\mathrm{a}}$ \\
\hline Irinotecan & 17 & 10.8 & 35 & 7.8 & $0.323^{\mathrm{a}}$ \\
\hline Carboplatin & 11 & 7.0 & 29 & 6.4 & $0.969^{\mathrm{a}}$ \\
\hline Cyclophosphamide & 9 & 5.7 & 5 & 1.1 & $<0.001^{\mathrm{a}}$ \\
\hline Cisplatin $\left(25-30 \mathrm{mg} / \mathrm{m}^{2}\right)$ & 2 & 1.3 & 14 & 3.1 & $0.338^{\mathrm{a}}$ \\
\hline \multicolumn{6}{|l|}{ Emetic risk } \\
\hline $\mathrm{HEC}+\mathrm{MEC}$ & 101 & 63.9 & 162 & 36.0 & $<0.001^{\mathrm{a}}$ \\
\hline Low + minimum & 57 & 36.1 & 288 & 64.0 & \\
\hline \multicolumn{6}{|l|}{ Cancer type } \\
\hline Breast & 49 & 31.0 & 81 & 18.0 & $<0.001^{\mathrm{a}}$ \\
\hline Colorectal & 42 & 26.6 & 100 & 22.2 & $0.315^{\mathrm{a}}$ \\
\hline Lung & 6 & 3.8 & 82 & 18.2 & $<0.001^{\mathrm{a}}$ \\
\hline Gastric & 23 & 14.6 & 63 & 14.0 & $0.968^{\mathrm{a}}$ \\
\hline Liver/gall bladder/pancreas & 10 & 6.3 & 48 & 10.7 & $0.150^{\mathrm{a}}$ \\
\hline Hematological & 6 & 3.8 & 17 & 3.8 & $1.000^{\mathrm{a}}$ \\
\hline Gynecological & 16 & 10.1 & 26 & 5.8 & $0.095^{\mathrm{a}}$ \\
\hline Adherence to antiemetic guideline & 146 & 92.4 & 420 & 93.3 & $0.831^{\mathrm{a}}$ \\
\hline
\end{tabular}

a Chi-square test

b Mann-Whitney $U$ test

${ }^{\mathrm{c}} t$ test

$88 \%$ for MEC, $99 \%$ for low-risk) for patients receiving the first cycle of chemotherapy, except for those undergoing CDDP-containing regimens (25\%). In the CDDPcontaining regimens used in the present study, the dose of CDDP was low $\left(25-30 \mathrm{mg} / \mathrm{m}^{2}\right)$; thus, aprepitant was excluded from the standard medication for HEC. Even such an antiemetic medication effectively prevented nausea and vomiting, in which the overall control rate was $88 \%$ for nausea and $94 \%$ for vomiting. Very recently, Tamura et al. [19] reported the effectiveness of the antiemetic guideline by a multi-institutional prospective observational study, showing that adherence to the guideline is approximately $74 \%$ for HEC and $95 \%$ for MEC. They also reported that adherence (three antiemetics containing aprepitant, 5- $\mathrm{HT}_{3}$ receptor antagonist, and dexamethasone) for HEC decreases the risk for delayed vomiting as compared with two antiemetics $\left(5-\mathrm{HT}_{3}\right.$ receptor antagonist and dexamethasone) without marked influence on the control of nausea.
In the present study, the rate of guideline consistency was generally consistent with the data reported by Tamura et al. [19], although the non-adherence did not affect the control of overall nausea or vomiting.

Under the condition of roughly consistent with guideline-recommended antiemetic medication, vomiting was fairly well controlled, but complete protection from nausea was not sufficient for HEC and MEC. The poor control of nausea for HEC in the first cycle occurred primarily in the A/C regimen for breast cancer. Tamura et al. [19] also reported the high incidence of delayed nausea $(49.4 \%$ for HEC and $41.7 \%$ for MEC), with a limited incidence of vomiting.

It was notable that the control of nausea and vomiting was generally higher in the overall cycles than in the first cycle. Particularly, marked improvement of the control rate of delayed nausea was observed at the second and third cycles of $\mathrm{A} / \mathrm{C}$ chemotherapy. It is unlikely that 
Table 3 Risk analysis for nausea and vomiting in 608 patients who underwent the first cycle of cancer chemotherapy

\begin{tabular}{|c|c|c|c|c|c|c|}
\hline & \multicolumn{3}{|c|}{ Univariate analysis } & \multicolumn{3}{|c|}{ Multivariate analysis } \\
\hline & Odds ratio $(\mathrm{OR})$ & $95 \%$ confidence interval & $P$ & OR & $95 \%$ confidence interval & $P$ \\
\hline \multicolumn{7}{|l|}{ Nausea } \\
\hline Female & 2.228 & $(1.524-3.258)$ & $<0.001$ & 1.615 & $(1.022-2.552)$ & 0.040 \\
\hline Age $<60$ years & 3.007 & $(2.070-4.369)$ & $<0.001$ & 2.303 & $(1.525-3.477)$ & $<0.001$ \\
\hline $\mathrm{HEC} / \mathrm{MEC}$ & 3.150 & $(2.160-4.595)$ & $<0.001$ & 2.321 & $(1.489-3.617)$ & $<0.001$ \\
\hline $\mathrm{A} / \mathrm{C}$ regimen & 10.554 & $(4.857-22.93)$ & $<0.001$ & 4.955 & $(1.863-13.18)$ & 0.001 \\
\hline Breast cancer & 2.048 & $(1.354-3.098)$ & 0.001 & 0.700 & $(0.375-1.306)$ & 0.262 \\
\hline Lung cancer & 0.177 & $(0.076-0.415)$ & $<0.001$ & 0.301 & $(0.125-0.725)$ & 0.007 \\
\hline Adherence to antiemetic guideline & 0.869 & $(0.434-1.742)$ & 0.692 & 0.960 & $(0.444-2.076)$ & 0.918 \\
\hline \multicolumn{7}{|l|}{ Vomiting } \\
\hline Female & 4.429 & $(1.923-10.20)$ & $<0.001$ & 3.151 & $(1.213-8.183)$ & 0.018 \\
\hline Age $<50$ years & 4.026 & $(1.997-8.117)$ & $<0.001$ & 5.803 & $(2.667-12.63)$ & $<0.001$ \\
\hline HEC/MEC & 4.152 & $(1.985-8.683)$ & $<0.001$ & 2.993 & $(1.245-7.195)$ & 0.014 \\
\hline $\mathrm{A} / \mathrm{C}$ regimen & 8.205 & $(3.684-18.27)$ & $<0.001$ & 2.987 & $(0.785-11.36)$ & 0.108 \\
\hline Breast cancer & 2.777 & $(1.420-5.427)$ & 0.003 & 0.527 & $(0.167-1.667)$ & 0.276 \\
\hline Lung cancer & 0.304 & $(0.072-1.283)$ & 0.105 & 0.759 & $(0.164-3.506)$ & 0.724 \\
\hline Adherence to antiemetic guideline & 0.883 & $(0.260-2.997)$ & 0.842 & 0.539 & $(0.138-2.110)$ & 0.375 \\
\hline
\end{tabular}
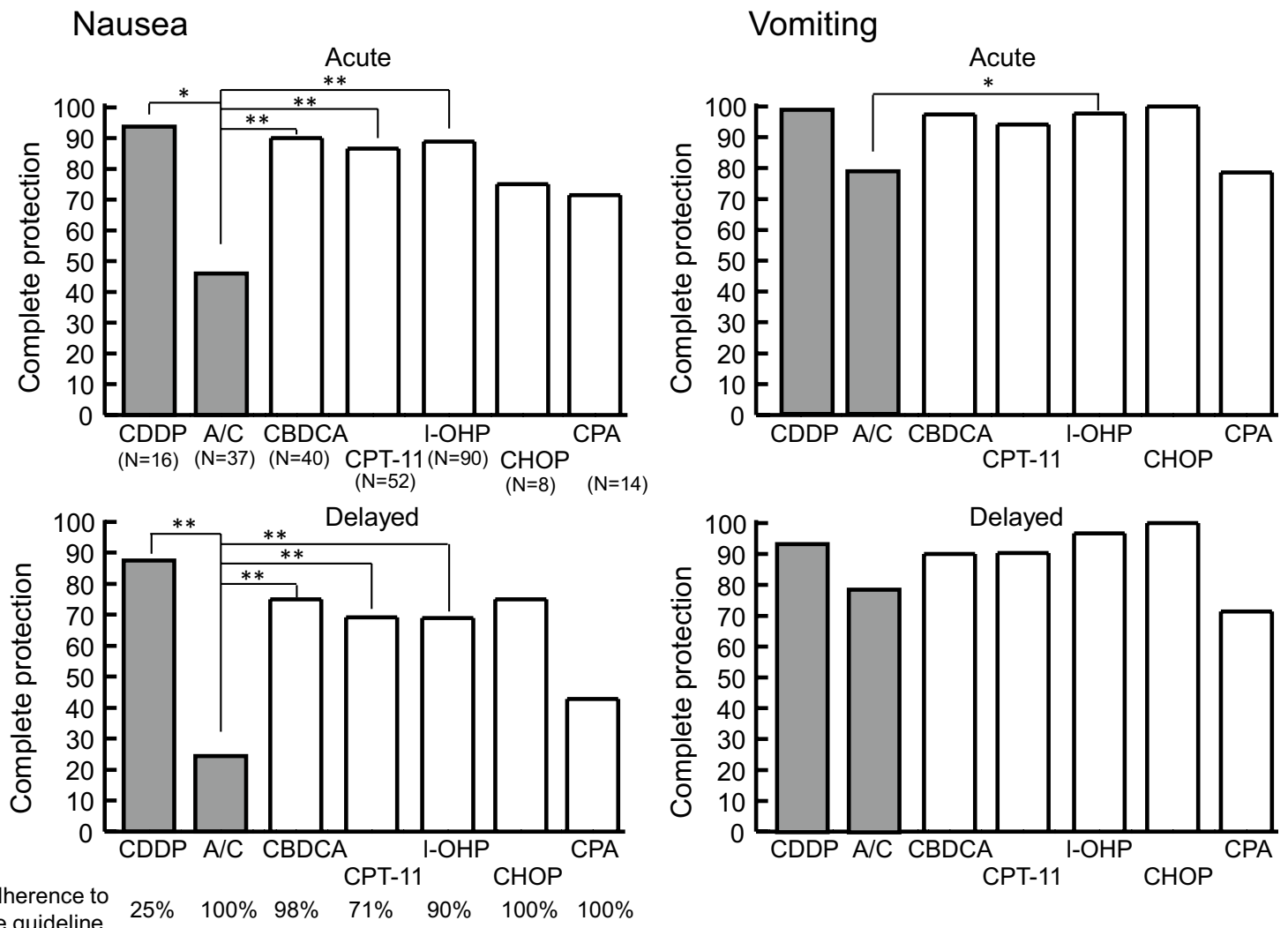

Fig. 2 Comparison of the rates of complete protection from nausea and vomiting among various chemotherapy regimens in patients receiving the first cycle of chemotherapy in the outpatient chemotherapy clinic. The number of patients $(n)$ is shown in each pair of parentheses. Adherence to the Japanese antiemetic guideline during the overall period is represented at bottom of figure. Shaded columns represent HEC; open columns exhibit MEC. $* P<0.05$, $* P<0.01$ by Kruskal-Wallis test followed by Scheffe's test 
Fig. 3 Change in the control of nausea and vomiting in patients receiving three consecutive cycles of anthracycline/cyclophosphamide $(\mathrm{A} / \mathrm{C})$ regimen. $* P<0.05, * P<0.01$ by Kruskal-Wallis test followed by Scheffe's test

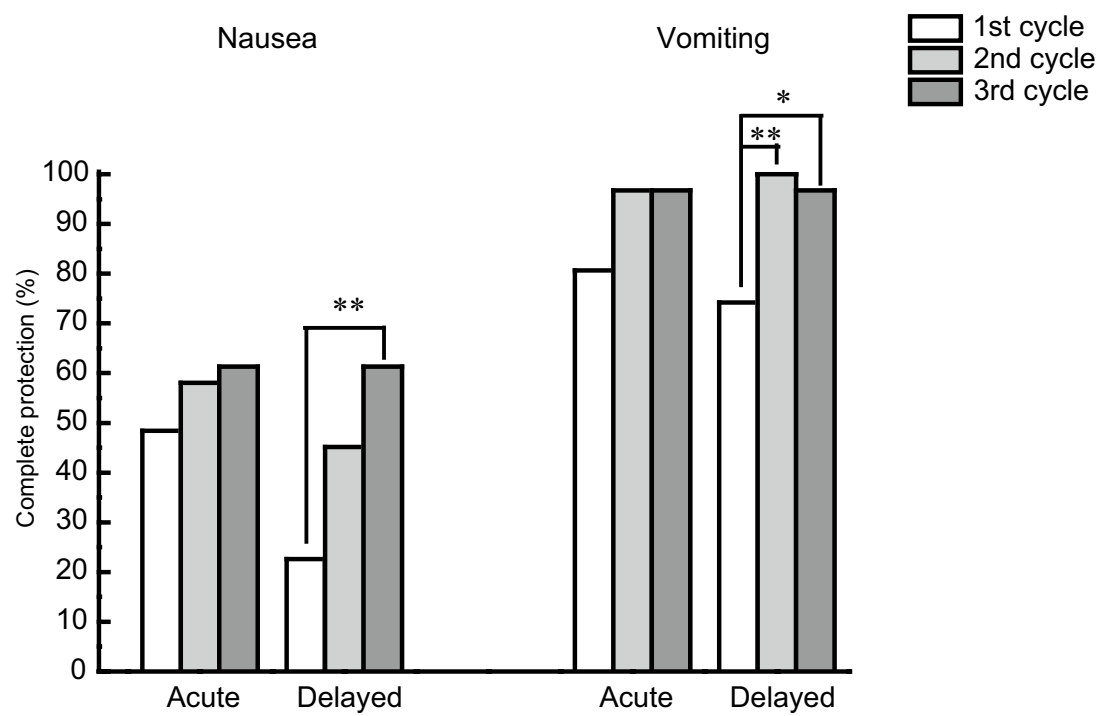

improvement of the control of nausea results from decrease in the dose of anticancer drugs because, in the present study, the dose reduction was not observed in the first cycle but was carried out in one patient in the second cycle (15\% reduction) as well as in the third cycle (15\% reduction). Patients who showed failure in the control of CINV in the previous cycle were administered prochlorperazine or olanzapine in addition to an antianxiety drug such as lorazepam in the following cycles, which may be the predominant reason for the improvement of CINV control in the subsequent cycles. Moreover, in 608 patients who received the first cycle of HEC, MEC, low, or minimal risk of chemotherapy, the dose intensity was quite similar between patients with and without complete protection from nausea, in which the values were $97.0 \pm 8.1 \%$ (mean $\pm \mathrm{SD}$ ) in 450 patients who showed complete protection from nausea and $97.0 \pm 7.5 \%$ in 158 patients who did not. In addition, the complete protection from nausea was $71.4 \%$ (60 of 84 patients) in patients with dose reduction and $74.4 \%$ (390 of 524 patients $)$ in those without dose reduction $(P=0.654$ by $\chi^{2}$ test). Therefore, it is unlikely that the dose of anticancer drugs affected the control of chemotherapy-induced nausea in the present study.

Several investigators have shown the risk factors for CINV. Female gender, age, no history of drinking, and history of hyperemesis gravidarum are common as risks that lead to a loss of control of CINV [19-26]. Sekine et al. [21] showed in patients receiving HEC or MEC that female gender has high risk (OR 2.49) for failure in complete response (no vomiting and no rescue). It has also been reported that female patients are more likely to experience nausea and vomiting than male patients receiving HEC or MEC [22, 23]. On the other hand, Hesketh et al. [24] reported in patients receiving CDDP $\left(\geq 70 \mathrm{mg} / \mathrm{m}^{2}\right)$ that females are at high risk for the inability to complete response (OR 1.303) only when aprepitant is not included in the antiemetic medication. Younger age is also a risk for the loss of emetic control, but the cutoff age differs among studies, ranging from 40 to 65 years old [20-23]. Tamura et al. [19] also reported that older age is a decreased risk for CINV. However, the cutoff value of age that influences the control of CINV is still unclear. In the present study, the cutoff value of age was estimated from the ROC curve method, in which the AUC was 0.658 for nausea (low accuracy prediction) and 0.721 for vomiting (moderate accuracy prediction). The cutoff age was 58.5 years old as determined by the Youden index or 61.5 years old by the distance method and was set at 60 years old. Interestingly, the cutoff age for vomiting predicted by Youden index and distance method (49.5 years old) was younger than that for nausea. As a consequence, age under 60 years old was a significant risk for nausea (OR 2.303; $95 \%$ CI, 1.525-3.477, $P<0.001$ ), whereas age under 50 years old was a significant risk for vomiting (OR 5.803; $95 \% \mathrm{CI}, 2.667-12.63, P<0.001$ ). In addition, female gender (OR $1.615 ; 1.022-2.552, P=0.04$ for nausea; OR $3.151 ; 1.213-8.183, P=0.018$ for vomiting) and HEC/MEC (OR 2.321; 1.489-3.617, $P<0.001$ for nausea; OR $2.993 ; 1.245-7.195, P=0.014$ for vomiting) were also significant risks for nausea or vomiting, although $\mathrm{A} / \mathrm{C}$ chemotherapy was a significant risk for nausea but not for vomiting (OR 4.955; 1.863-13.18, $P=0.001$ ). Our present findings indicating the difference in the cutoff age between nausea and vomiting suggest that the differences in the cutoff age among studies may result from different indices of the control of CINV, including complete response, complete control, and complete protection from nausea or vomiting.

These findings, taken together, suggested that extensive antiemetic medication using other types of antiemetic drugs such as olanzapine in addition to the standard medication is required for prevention of chemotherapy-induced 
nausea in patients who possess risks for poor control of $\mathrm{CINV}$, including being female, younger age, and $\mathrm{A} / \mathrm{C}$ chemotherapy.

In the present study, no marked difference in the control of CINV among MEC except for cyclophosphamide-base regimens other than the $\mathrm{A} / \mathrm{C}$ regimen, although there was a marked difference in the control of CINV among HEC, as mentioned earlier. The low rate of the control of CINV for cyclophosphamide-base regimens may be caused by the patient risks (female and young age) rather than the chemotherapy, because the cyclophosphamide-base regimens were used for the most part in breast cancer patients, whose average age was 48 years.

In conclusion, the control of CINV was investigated in 779 patients receiving 5511 cycles of chemotherapy regimens in our outpatient cancer chemotherapy clinic. In spite of the high rate of adherence to the antiemetic guideline, the control of nausea, but not vomiting, was poor in patients receiving HEC and MEC. A multivariate logistic regression analysis indicated that female gender, age under 60 years, HEC/MEC, and A/C chemotherapy were significant risks for overall nausea. Care should be taken to prevent chemotherapy-induced nausea in high-risk patients.

\section{Compliance with ethical standards}

Conflict of Interest The authors declare that they have no conflict of interest.

Open Access This article is distributed under the terms of the Creative Commons Attribution 4.0 International License (http://creativecommons.org/licenses/by/4.0/), which permits unrestricted use, distribution, and reproduction in any medium, provided you give appropriate credit to the original author(s) and the source, provide a link to the Creative Commons license, and indicate if changes were made.

\section{References}

1. de Boer-Dennert M, de Wit R, Schmitz PI et al (1997) Patient perceptions of the side-effects of chemotherapy: the influence of 5HT3 antagonists. Br J Cancer 76:1055-1561

2. Carelle N, Piotto E, Bellanger A et al (2002) Changing patient perceptions of the side effects of cancer chemotherapy. Cancer (Phila) 95:155-163

3. Gralla RJ, Osoba D, Kris MG et al (1999) Recommendations for the use of antiemetics: evidence-based, clinical practical guidelines. J Clin Oncol 17:2971-2994

4. Basch E, Prestrud AA, Hesketh PJ et al (2011) American Society of Clinical Oncology. Antiemetics: American Society of Clinical Oncology clinical practice guideline update. J Clin Oncol 29:4189-4198

5. Roila F, Herrstedt J, Aapro M, ESMO/MASCC Guidelines Working Group et al (2010) Guideline update for MASCC and ESMO in the prevention of chemotherapy- and radiotherapyinduced nausea and vomiting: results of the Perugia consensus conference. Ann Oncol 21(suppl 5):v232-v243
6. National Comprehensive Cancer Network (NCCN) Clinical Practice Guidelines in Oncology (NCCN Guidelines ${ }^{\circledR}$ ). Antiemesis Version 1.2015: http://www.nccn.org/professionals/physician_gls/pdf/antiemesis.pdf

7. Takeuchi H, Saeki T, Aiba K, et al (2015) Japanese Society of Clinical Oncology clinical practice guidelines 2010 for antiemesis in oncology: executive summary. Int $\mathrm{J}$ Clin Oncol. doi:10.1007/s10147-015-0852-1

8. Wickham R (2010) Best practice management of CINV in oncology patients: II. Antiemetic guidelines and rationale for use. J Support Oncol 8(2 suppl 1):10-15

9. Gomez DR, Liao KP, Giordano S et al (2013) Adherence to national guidelines for antiemesis prophylaxis in patients undergoing chemotherapy for lung cancer: a population-based study. Cancer (Phila) 119:1428-1436

10. Hori K, Kobayashi N, Atsumi H et al (2014) Changes in compliance with Japanese antiemetic guideline for chemotherapyinduced nausea and vomiting: a nationwide survey using a distributed research network. Support Care Cancer 22:969-977

11. Chan A, Low XH, Yap KY (2012) Assessment of the relationship between adherence with antiemetic drug therapy and control of nausea and vomiting in breast cancer patients receiving anthracycline-based chemotherapy. J Manag Care Pharm 18:385-394

12. Aapro M, Molassiotis A, Dicato M et al (2012) PEER investigators. The effect of guideline-consistent antiemetic therapy on chemotherapy-induced nausea and vomiting (CINV): the Pan European Emesis Registry (PEER). Ann Oncol 23:1986-1992

13. Gilmore JW, Peacock NW, Gu A et al (2014) Antiemetic guideline consistency and incidence of chemotherapy-induced nausea and vomiting in US community oncology practice: INSPIRE Study. J Oncol Pract 10:68-74

14. Fujii H, Iihara H, Ishihara $M$ et al (2013) Improvement of adherence to guidelines for antiemetic medication enhances emetic control in patients with colorectal cancer receiving chemotherapy of moderate emetic risk. Anticancer Res 33:5549-5556

15. Roscoe JA, Heckler CE, Morrow GR et al (2012) Prevention of delayed nausea: a University of Rochester Cancer Center Community Clinical Oncology Program study of patients receiving chemotherapy. J Clin Oncol 30:3389-3395

16. Farrell C, Brearley SG, Pilling M et al (2013) The impact of chemotherapy-related nausea on patients' nutritional status, psychological distress and quality of life. Support Care Cancer 21:59-66

17. Akobeng AK (2007) Understanding diagnostic tests 3: receiver operating characteristic curves. Acta Paediatr 96:644-647

18. Hajian-Tilaki K (2013) Receiver operating characteristic (ROC) curve analysis for medical diagnostic test evaluation. Casp J Intern Med 4:627-635

19. Tamura K, Aiba K, Saeki T, et al; CINV Study Group of Japan (2015) Testing the effectiveness of antiemetic guidelines: results of a prospective registry by the CINV Study Group of Japan. Int J Clin Oncol. doi:10.1007/s10147-015-0786-7

20. Booth CM, Clemons M, Dranitsaris G et al (2007) Chemotherapy-induced nausea and vomiting in breast cancer patients: a prospective observational study. J Support Oncol 5:374-380

21. Sekine I, Segawa Y, Kubota K et al (2013) Risk factors of chemotherapy-induced nausea and vomiting: index for personalized antiemetic prophylaxis. Cancer Sci 104:711-717

22. Hilarius DL, Kloeg PH, van der Wall E et al (2012) Chemotherapy-induced nausea and vomiting in daily clinical practice: a community hospital-based study. Support Care Cancer 20:107-117

23. Fraunholz I, Grau K, Weiss C et al (2011) Patient- and treatmentrelated risk factors for nausea and emesis during concurrent chemoradiotherapy. Strahlenther Onkol 187:1-6 
24. Hesketh PJ, Aapro M, Street JC et al (2010) Evaluation of risk factors predictive of nausea and vomiting with current standardof-care antiemetic treatment: analysis of two phase III trials of aprepitant in patients receiving cisplatin-based chemotherapy. Support Care Cancer 18:1171-1177

25. Warr DG, Street JC, Carides AD (2011) Evaluation of risk factors predictive of nausea and vomiting with current standard-ofcare antiemetic treatment: analysis of phase 3 trial of aprepitant in patients receiving adriamycin-cyclophosphamide-based chemotherapy. Support Care Cancer 19:807-813

26. Furukawa N, Akasaka J, Shigemitsu A et al (2014) Evaluation of the relation between patient characteristics and the state of chemotherapy-induced nausea and vomiting in patients with gynecologic cancer receiving paclitaxel and carboplatin. Arch Gynecol Obstet 289:859-864 